\title{
Communication Richness: Why Some Guest Complaints Go Right to the Top-and Others Do Not
}

Cornell Hospitality Quarterly

$1-12$

(C) The Author(s) 2014

Reprints and permissions: sagepub.com/journalsPermissions.nav DOI: |0.||77/|9389655|4560|6| cqx.sagepub.com

@SAGE

\author{
Alex M. Susskind ${ }^{\prime}$
}

\begin{abstract}
Despite everyone's best efforts, restaurant service falls short at times. In those situations, guests perceive a service failure, and many complain. This study of 513 guests in three U.S. markets examines the guest characteristics that seem to drive the channel used for those complaints. Using a framework of media richness theory, the study found that guests who are more educated, more likely to complain, more frustrated, and in need of greater information about the service failure will typically take their complaint directly to management, either face-to-face or via written communication. On the other hand, those who are less educated or less frustrated will instead complain to line staff or use corporate guest-comment cards. Some of these findings appear not to support media richness theory, as face-to-face complaints are the richest channel (whether to line staff or management). However, it appears that for this sample of restaurant guests, the idea of taking it to the top (both in person or in writing) is important, particularly for frustrated, educated guests.
\end{abstract}

\section{Keywords}

food and food service; operations; multi-unit restaurant management; complaint communication, customer satisfaction; Media Richness Theory.

When a service encounter fails in some way, guests and service providers alike attempt to understand what went wrong, what can be done to fix it, and what could be done to prevent it from happening again. The starting point for this investigation is often a complaint lodged by the guest. Most restaurateurs (and operators of other service-based organizations) solicit guest comments and complaints as a means of ensuring customer satisfaction and a reduction of error. For the guest, a complaint is a way to inform the service provider of a problem. For operators, complaints act as a gauge of their performance and offer an avenue to improve their performance.

Despite the importance of guest complaints, we still do not have a firm indication of why guests choose a particular channel for their complaint. In this article, I examine guest complaints in connection with media richness theory to gain a greater understanding of guest preferences with regard to complaint channels. Based on the consumer-frustration hypothesis (Berkowitz 1989; Susskind 2004) and guests' perceptions of the complaint process (Day 1984; Kowalski 1996; Susskind 2002, 2005), I present elements of media richness theory (Daft and Lengel 1984, 1986) as a framework to demonstrate the objective decisions guests make when they make a complaint due to dissatisfaction with a service experience.

I will begin with a discussion of media richness theory and show how it relates to complaint communication. Next,
I will describe complaints and complaint management in general, and outline three variables - propensity to complain, information inadequacy, and consumer frustrationthat underlie how guests process service failures and their subsequent decisions to complain. Finally, I will present, test, and discuss the findings for three research questions in connection with those three variables.

\section{Media Richness Theory}

Media richness theory is a way to classify messages that vary in complexity and meaning, in this case, service-based complaints. The idea behind this theory is that individuals continually exchange information (Daft, Lengel, and Trevino 1987; Robert and Dennis 2005), but each exchange entails varying levels of certainty (lack of information) and equivocality (ambiguity). Uncertainty is normally reduced by receiving more data, while equivocality is normally reduced by discussion and debate. In general, to reduce equivocality, one uses richer communication channels, such

'Cornell University, Ithaca, NY, USA

Corresponding Author:

Alex M. Susskind, School of Hotel Administration, Cornell University, 350 Statler Hall, Ithaca, NY I4853, USA.

E-mail:ams76@cornell.edu 
as personal contact, while uncertainty, in contrast, can be reduced with less-rich communication channels, such as writing (Daft, Lengel, and Trevino 1987). Richer communication channels have been shown to facilitate social perceptions of others and enhance the ability to evaluate interpersonal communication elements such as expertise, deception, agreement, acceptance, and persuasion. Leaner communication channels, on the other hand, have been shown to facilitate communication clarity when task-relevant knowledge is low (Kahai and Cooper 2003). In addition, with richer communication channels, the sender must have the receiver's attention to effectively deliver the message (Robert and Dennis 2005). This is based on the premise that richer communication will require more effort but will then hopefully lead to a more desirable result and facilitate better understanding on the part of both the sender and receiver (Robert and Dennis 2005).

Media richness has been studied in several domains, notably in the use and adoption of technology, computermediated communication (Daft, Lengel, and Trevino 1987; Dennis and Kinney 1998; Kahai and Cooper 1999, 2003; Schmitz and Fulk 1991), and task performance and decision making (Dennis, Kinney, and Hung 1999; Kahai and Copper 1999, 2003; Robert and Dennis 2005). These studies have demonstrated the contrasting value of leaner and richer communication channels. Richer communication channels, for instance, result in better decision making, greater socioemotional communication, and greater task-oriented communication (Kahai and Cooper 2003). In addition, the use of richer communication leads to greater agreement with and acceptance of decisions (Kahai and Cooper 1999). On the other hand, Dennis, Kinney, and Hung (1999) found that the use of leaner communication channels resulted in lower performance because it took more time to reach a decision, but leaner communication channels did not affect decision quality or performance itself.

The richness of each communication channel is characterized by four qualities of information-carrying ability and exchange: (1) the capability to provide direct, rapid feedback to the receiver of the message (synchronous vs. asynchronous); (2) the number of communication channels and cues utilized to convey the message (such as verbal communication and nonverbal communication); (3) the use of natural language to convey the message; and (4) the source or focus of the communication (Daft and Lengel 1984, 1986). Based on these four qualities, face-to-face interactions have been classified as the "richest" communication channel, and consequently, that channel is the benchmark to which emerging communication forms have been compared (Daft and Lengel 1984, 1986; Trevino, Lengel, and Daft 1987).

Communication channel richness also suggests that richer communication channels are more capable of conveying multiple cues beyond words, thereby enabling rapid, synchronous feedback and facilitating efficient information seeking and communication. Although guests do not expressly consider media richness theory when they need to communicate a complaint, they do examine the elements of the service failure, consider the different communication channels available to complain, and then choose the communication channel (or the combination of channels) that will get their message across regarding the unsatisfactory service experience (and its potential remedy).

In that context, the channels available to complaining guests would be (in descending order of richness) faceto-face communication with a manager, face-to-face communication with an employee, written communication directed to management (via letter, e-mail, or the internet), and (least rich) a comment card. Face-to-face communication with a manager or supervisor is richest because (in addition to using multiple cues) the manager has more control and authority to provide direct and immediate feedback and a solution to address the guest's concerns and can quickly react to issues that surface. Although face-to-face communication with an employee has almost as much richness as communication with a manager, the employee is not always capable of or empowered to offer a direct, agreeable solution to guests. So, even if the feedback can be immediate and synchronous, there may be limits on how the solution is derived and executed. Written communication (regardless of channel) is less rich because it offers neither multiple cues nor a direct mechanism for immediate feedback. Although the sender may expect a response in kind, not all hospitality organizations respond to internet comments, even though they monitor them (see, for example, Park and Allen 2013). Comment cards are the least rich form of communication because they also fail to offer multiple cues. Moreover, in most cases, the comment cards are completed anonymously so there is little or no expectation of direct feedback from the operator. Beyond that, comment cards are not always completed with a particular receiver in mind (or, more on point, the guest does not know who will read them).

The guest's choice of a specific communication channel to lodge a complaint is based on the belief that the communication will have the intended effect on the person who receives the complaint. As noted by Robert and Dennis (2005), communication is first designed to get the attention of the receiver. For example, if you had a hard time getting your server to refill your beverage at the table (and wanted the problem solved during your meal), you would most likely directly ask your server to fill the glass. If that request was still not successful, however, you might flag down another server or a manager to resolve the service failure, or in media-richness terms, use richer, face-to-face contact to get the attention of the server or manager. For a potentially less critical or urgent matter (e.g., not liking the music or artwork), you might complete a low-richness comment card to complain rather than engaging a person directly. 


\section{Complaint Behavior}

At root, for a complaint to take place, a guest must first identify an element of the service process that was not to his or her liking, determine that it should be corrected, determine who can or will correct it, and then select an approach to deliver the complaint. The media-richness framework suggests that the guest will choose the richest possible channel for a complaint because it involves a socioemotional communication, and communication of this type best suited for richer communication channels (Kahai and Cooper 2003).

Particularly, if it involves a rich, face-to-face channel, a complaint constitutes a social confrontation. As a consequence, an individual's desire to complain about a dissatisfying service experience is based on his or her self-efficacy, which in turn involves the individual's estimate of whether she is able to make a complaint that successfully redresses a dissatisfying experience. For the individual, self-efficacy regarding a particular complaint then leads to outcome expectancy, which is the perception that the effort expended in voicing the complaint will lead to a desired resolution. Due to self-regulation, individuals vary in how they respond to dissatisfying experiences (Bagozzi 1992; Maddux, Norton, and Stoltenberg 1986; Singh and Wilkes 1996), based on their gauge of self-efficacy (Makoul and Roloff 1998; Susskind 2000).

Taking this mechanism one step farther, self-efficacy theory is a subset of expectancy-valence theories, where the propensity to engage in a specific behavior (such as communicating a complaint) is the product of the reinforcement value of an expected outcome and the expectation that specific behaviors will lead to that outcome (Bagozzi 1992; Maddux, Norton, and Stoltenberg 1986; Singh and Wilkes 1996). In general, investigations addressing self-efficacy have shown that efficacy expectations to perform a specific behavior (like a complaint) lead to specific outcome expectations for that behavior (the desired remedy). More formally, efficacy expectations spawn intentions to perform a specific behavior and, further, the specific performance of behaviors (Susskind 2000, 2005). At a practical level, guests will not initiate a social confrontation if they do not believe from the start that they have a chance at being successful. This is one explanation for the phenomenon that not all consumers will complain when dissatisfied. Noncomplainers either make an assessment that the situation is not within their control, deny that the problem exists, or avoid the situation by exiting and not lodging a complaint (Singh 1988; Stephens and Gwinner 1998).

Recently, hospitality researchers have done a thorough job of exploring the socioemotional antecedents and outcomes related to complaints in service episodes that are germane to this study. Mattila and Ro (2008), for example, found that anger that emerged from a service failure was directly connected to guests' desire to complain faceto-face to the service provider. This demonstrates that angry guests prefer richer communication channels. Sparks and Fredline (2007) have identified the role that mitigating information plays in service recovery, finding that referential explanations (information about the service failure, rather than justifications) by service providers were connected to higher levels of satisfaction and loyalty among guests. While many dimensions of the service process have been examined with regard to guest satisfaction, the connection between communication channel selected for a complaint and how guests process complaints remains less than clear in service-based settings.

In this paper, I attempt to further our understanding of how guests process complaints by examining the relationship between the channel of communication guests select to complain about service failures and the following underlying factors: (1) their propensity to complain when dissatisfied, (2) their perceptions of information inadequacy about service experiences, and (3) their frustration with service experiences.

\section{Propensity to Complain}

There are a number of factors that drive guests' motivation to complain about service experiences. The decision process for the guest typically involves (1) a cognitive evaluation of the relevance of the service failure, (2) the guests' knowledge and experience with similar service-based failures, (3) the specific limitations of complaining in the particular instance, and (4) the likelihood of success in complaining (Day 1984). Based on these elements, guests consider the extent to which they believe that they (1) are able to effectively complain about the dissatisfying situation and (2) believe that their complaint will lead to a desired remedy or expectancy (Singh 1988; Singh and Wilkes 1996; Susskind 2000). This outline of the complaint process highlights in general how guests form specific attitudes and beliefs toward the act of complaining and how they assign value to it. This process could be defined as a global attitude toward complaining that is based on a collection of many experiences, not one alone (Susskind 2002, 2005; Susskind and Viccari 2011). When a guest experiences a service failure and determines that a remedy might be required, the particular service failure will prompt the guest to determine whether a complaint should be lodged in that instance and the appropriate communication channel for lodging the complaint. The guest also gauges the probability that a desired outcome will emerge from making a complaint (Kowalski 1996; Sparks and Fredline 2007; Susskind 2000). Those who are predisposed to complain when dissatisfied are more likely to voice their concerns directly to the seller (Huppertz, Mower, and Associates 2003). This has implications regarding the richness of the 
communication channel selected for the complaint, because a propensity to complain could be framed as a socioemotional characteristic, associated with the desire to use a richer communication channel (Kahai and Cooper 2003). ${ }^{1}$

\section{Guest Frustration}

For the purposes of this study, guest frustration is defined as a negative emotional reaction to particular elements of a service experience (Susskind 2004). In service experiences, guests become frustrated when the attainment of a specific desired outcome is blocked. Triggers of frustration in restaurants include waiting for food or a table, receiving incomplete or incorrect food and beverage orders, poor food or service quality, and discordant elements of the décor and atmosphere. Frustration also emerges in all hospitality organizations when you feel you have been not been treated properly.

Service failure fits into the frustration-aggression hypothesis (Berkowitz 1989; Dollard et al. 1939), which presented an early example of how the blocking of the attainment of expected outcomes likely leads to increased perceptions of frustration. ${ }^{2}$ This phenomenon was tested by Harris (1974), when he had his research assistants cut in front of guests who were waiting in line for retail services. He found that guests became more frustrated with the "line cutting" as the size of the line increased. This suggests that guest frustration emerges when guests see an object blocking their receiving a product or service for which they are waiting. The potential for frustration in service experiences starts with the fact that consumers must give up direct control of the service experience to receive the products and services they expect (Guchait and Namasivayam 2012). If factors beyond their control interfere with a service experience, frustration is a likely outcome (Susskind 2004).

Frustration is an important foundation of the complaint process that is related not only to a failed outcome but also to a lack of information. This was the source of frustration in one study I conducted (Susskind 2004), which found that retail consumers' frustration was related to their need for information, such that shoppers who felt they needed more information regarding their shopping experience reported higher levels of frustration.

\section{Information Inadequacy}

This issue of information inadequacy is related to consumers' need for control in the service experience (Guchait and Namasivayam 2012). As guests evaluate the conditions surrounding a service failure, they will likely seek information regarding that failure. This information helps guests process and put closure on the failure and its surrounding circumstances as they attempt to regain a sense of control of the service experience. With mitigating information, the guest is able to make attributions about the service failure that affected them, determine how serious the service failure is, and decide what should be done about it. Guests also require information about service failures to help them better understand the technical or hidden aspects of the service delivery processes (Mittal, Huppertz, and Khare 2008). In this regard, better informed customers make better decisions about how to proceed following service failures (Hui and Tse 1996). For example, a guest who is told they will have to wait one hour for a table in a restaurant, yet sees an entire section of the dining room apparently available, would appreciate knowing why the restaurant is not seating people in that section.

If insufficient or inaccurate information is provided to the guest following a service failure, it adds uncertainty to the service experience, limits the guests' ability to evaluate the cause and effect of the service failure, and likely leads to frustration (Fornell and Westbrook 1979; Susskind 2004). Furthermore, guests who cannot attribute the cause of a service failure to either internal or external causes are more likely to create a negative image of the event (Mattila and Ro 2008; Sparks and Fredline 2007).

Guests who experience information inadequacy as a result of a service failure will likely seek a richer form of communication to deliver their complaint. This proposed relationship is based on the premise of information control, where more informed guests are likely to share their views about the service failure to restore balance in the service exchange with the service provider (Mittal, Huppertz, and Khare 2008; Susskind 2004), as opposed to defecting, switching, or engaging in negative word-of-mouth communication (Mattila and Ro 2008).

Based on the above discussion, I examine guests' reactions to service failures and remedies by looking at several personal factors that influence their desire to complain and the way in which they choose to complain, as stated in the following four research questions:

Research Question 1: What is the relationship between the communication channels guests choose to express their dissatisfaction with a service experience and their propensity to complain?

Research Question 2: What is the relationship between the communication channels guests choose to lodge a complaint about a service experience and their need for information regarding service failures?

Research Question 3: What is the relationship between the communication channels guests choose to lodge a complaint about a service experience and their level of guest frustration?

Research Question 4: What is the relationship between the communication channels guests choose to lodge a complaint about a service experience and their sociodemographic characteristics? 


\section{Method}

\section{Participants and Procedure}

To test these proposed relationships, we surveyed 513 mall patrons whom we solicited while they were shopping in three U.S. cities adjacent to college campuses located in the Northeast, Southeast, and Midwest. Over the course of six months, we set up tables in front of the malls' food court between the hours of noon and 3:00 p.m. and from 6:00 to 8:00 p.m. on both weekdays and weekends. The participants in this convenience sample were asked to fill out the survey if they met the following three criteria: (1) they had eaten a meal in a table-service restaurant in the prior three months, (2) they had experienced some type of a service failure during their meal, and (3) they had lodged a complaint during or following that meal. Participants were given a lottery ticket costing $\$ 1.00$ in exchange for their completed survey. We asked a total of 900 shoppers to participate, yielding the 513 participants who both qualified and agreed to participate in the study (a response rate of 57 percent).

The average age of the study participants was 32.10 years, ranging from 18 to $73 ; 59$ percent of the study participants were women; 15.2 percent reported they held only a high school diploma, 7 percent had graduated from an associate's degree program or technical program, 42 percent indicated they hold a bachelor's degree or were currently earning one, and 36 percent reported they hold a graduate level degree or were currently earning one. On average, the participants reported they eat about three lunches and not quite three dinners a week in a restaurant, ranging from never to every day (lunch, $M=3.12$; dinner, $M=2.53$ ). See Exhibit 1 for a summary of the participants' sociodemographic character-istics that were measured categorically.

Measurement. The participants were also asked to select the channel of communication they prefer to use for restaurant service complaints from the list we discussed above: (1) face-to-face with a manager, (2) face-to-face with an employee, (3) written (either letter, e-mail, or the web), or (4) the organization's comment cards. These preference data are also summarized in Exhibit 1.

The participants' frustration level was measured using three items, and perceived information inadequacy was measured using five items, all of which I developed for an earlier study (Susskind 2004). Attitudes toward complaining were measured using four items developed by Day (1984), which I also adjusted for service encounters. The respondents were asked to indicate their level of agreement with each statement using a five-point Likert-type scale (anchored by strongly agree $=5$ and strongly disagree $=1$ ). The survey items are presented in Exhibit 2.

All of the scales used in this study were content validated using Hinkin and Tracey's (1999) approach (cf. Susskind
Exhibit 1:

Communication Channel Preferences to Complain and the Categorical Socio-Demographic Variables.

\begin{tabular}{lrr}
\hline & $N$ & $\%$ \\
\hline Preferred communication channel & & \\
Face-to-face with manager & 246 & 48 \\
Face-to-face with employee & 140 & 27 \\
Written (letter, e-mail, web) & 84 & 17 \\
$\quad$ Comment card & 42 & 8 \\
Education level & & \\
$\quad$ High school graduate & 78 & 15.2 \\
Associates/technical & 36 & 7.0 \\
Bachelor's & 215 & 41.9 \\
Graduate & 184 & 35.9 \\
Income level & & \\
$\$ 19,999$ or less & 17 & 3.3 \\
$\$ 20,000$ to $\$ 49,999,000$ & 148 & 28.8 \\
$\$ 50,000$ to $\$ 99,999$ & 217 & 42.3 \\
$\$ 100,000$ plus & 131 & 25.5 \\
Sex & & \\
$\quad$ Female & 303 & 59.06 \\
Male & 211 & 40.94 \\
\hline
\end{tabular}

\section{Exhibit 2:}

\section{Survey Items.}

Consumer frustration (adapted from Susskind 2004)

I. I often get upset when I don't get what I expect in service experiences.

2. Customer service employees who don't care about me make me mad.

3. When service is not right in some way, it's not the mistakes that bother me it's how the employees handle them with me. Information Inadequacy (adapted from Susskind 2004)

I. When service is not right in some way, it frustrates me when I don't get accurate information from the service providers.

2. I wish service providers would be more honest with me when problems occur with service.

3. I wish service providers would inform me when they know a problem has occurred with their ability to serve me.

4. I feel like service providers rarely give me enough information when service problems occur (like airline flight delays).

5. At times I feel I would be less irritated when service problems occur if I received more information about what went wrong.

Customers' Attitude Toward Complaining (adapted from Day 1984; Susskind 2004)

I. Complaining is a consumers' right not an obligation.

2. I always complain when I am dissatisfied because I feel it my duty.

3. Complaining isn't always easy, but it should be done when "things" are not right.

4. I always feel better once I voice my dissatisfactions through a complaint. 
Exhibit 3:

Principal Components Analysis of Survey Items.

\begin{tabular}{lrrr}
\hline & 1 & 2 & 3 \\
\hline Complaint I & .314 & -.075 & .744 \\
Complaint 2 & -.173 & .131 & .745 \\
Complaint 3 & .200 & -.096 & .754 \\
Complaint 4 & .092 & .228 & .754 \\
Frustration I & .214 & .866 & .083 \\
Frustration 2 & .262 & .871 & .036 \\
Frustration 3 & .195 & .840 & .041 \\
Info. Deficiency I & .665 & .284 & .100 \\
Info. Deficiency 2 & .709 & .177 & .183 \\
Info. Deficiency 3 & .735 & .173 & .164 \\
Info. Deficiency 4 &. $\mathbf{6 9 3}$ & .131 & -.096 \\
Info. Deficiency 5 & .731 & .102 & .111 \\
\hline
\end{tabular}

2004). To ensure that the scale items in this setting maintained the specified factor structure, the items were also subjected to a principal components analysis using a covariance matrix as input with a Varimax rotation. Results of the factor analyses (see Exhibit 3) support the factor structure I found in my earlier study (Susskind 2004), as all of the items loaded on their a priori specified factors with no notable cross loadings and acceptable levels of measurement reliability (Cronbach's $\alpha$ values are reported in the diagonal of the correlation matrix presented as Exhibit 4).

Analyses. To answer the research questions, I applied multivariate analysis (MANOVA) to test the mean values of guests' propensity to complain, perceptions of information adequacy, and perceived frustration (as the dependent variables) compared with the channel of communication guests prefer to use when lodging complaints. I also entered the sociodemographic variables of age, sex, education level, income level, and dining frequency into the equation as covariates. Following the multivariate analyses, one-way analysis of variance (ANOVA) with a post hoc Duncan's multiple range test was used to test the magnitude and significance of the differences noted in the dependent variables across the four channels of complaint communication, and the categorical and ordinal sociodemographic variables. In addition to the MANOVA and one-way ANOVA analyses, I assessed the correlations among the continuous variables age and dining frequency, examined the effect of sex using an independent sample $t$ test, and also analyzed the correlations among the ordinal variables of education and income.

\section{Results}

\section{Multivariate Analysis}

In general, the media richness theory did not entirely describe this sample's complaint communication preferences, although elements of the theory are applicable, as I will explain. That said, the multivariate model fit the data quite well, indicating that the channel of communication used by restaurant guests to report a service failure was associated with varying levels of their propensity to complain, their reported level of information adequacy, and their frustration with service failures. The Hotelling Trace Statistic was significant $(.40, p<.001)$ with an $F$ statistic of $F(9,1493)=22.01, p<.001, \eta^{2}=.12$. Propensity to complain explained the largest amount of variance in the model $\left(\eta^{2}=.25\right)$ followed by information inadequacy $\left(\eta^{2}=.16\right)$ and consumer frustration $\left(\eta^{2}=.10\right)$, confirming the multivariate model's sound fit to the data. The multivariate analyses also revealed that the participants' sex and education level were significant in the model. The Hotelling Trace Statistic was significant for respondent sex $(.02, p=.03)$ with an $F$ statistic of $F(3,499)=2.91, p=.04, \eta^{2}=$ .02 , and for level of education $(.06, p<.001)$ with an $F$ statistic of $F(3,497)=9.81, \mathrm{p}<.001, \eta^{2}=.06$. I discuss the significant effects and further describe them through one-way ANOVA, $t$-tests, and correlations.

\section{One-Way ANOVA}

While several variables tested in the multivariate model and the between-subjects model were identified as significant, the one-way ANOVAs revealed mixed support for the application of a media-richness complaint framework. Several interesting relationships emerged from the data, as follows (see Exhibit 5).

Propensity to complain. In the test of Research Question 1, the one-way ANOVA results revealed significant differences among the means across the four communication modes, $F(3,509)=53.12, p<.000$. Results from Duncan's multiple range tests indicated that face-to-face communication with a manager and a written letter to management were statistically different from both face-to-face communication with an employee and an organizationally provided comment card at the $p<.001$ level. This shows that guests who reported a higher propensity to complain about dissatisfying experiences indicated that complaining directly to a manager or drafting a letter to the company was their preferred choice of communication channel for lodging a complaint about their service experience as opposed to directing complaints to line-level employees or using an organization-provided comment card.

Information adequacy. Through the test of Research Question 2 , the one-way ANOVA results revealed significant differences among the means across the four communication modes, $F(3,509)=21.53, p<.001$. Results from Duncan's multiple range tests indicated that face-to-face communication with a manager and a written letter to management were statistically different from both face-to-face communication 
Exhibit 4:

Means, Standard Deviations, and Correlations Among the Variables.

\begin{tabular}{|c|c|c|c|c|c|c|c|c|c|c|c|}
\hline & M & SD & (I) & (2) & (3) & (4) & (5) & (6) & (7) & (8) & (9) \\
\hline (I) Sex & - & - & {$[-]$} & & & & & & & & \\
\hline (I) Age & 32.10 & 14.58 & $.09 *$ & {$[-]$} & & & & & & & \\
\hline (2) Education ${ }^{\dagger}$ & 3.99 & 1.01 & -.02 & .03 & {$[-]$} & & & & & & \\
\hline (3) Income ${ }^{\dagger}$ & 2.58 & 1.24 & $-.23 * *$ & $.1 I^{*}$ & $.28 * *$ & {$[-]$} & & & & & \\
\hline (4) Weekly Lunch Frequency & 3.12 & 2.15 & -.08 & $-.39 * *$ & $-.17^{* *}$ & $-.12 * *$ & {$[-]$} & & & & \\
\hline (5) Weekly Dinner Frequency & 2.53 & 1.96 & $-.16 * *$ & $-.38 * *$ & -.10 & -.05 & $.57^{* *}$ & {$[-]$} & & & \\
\hline (6) Propensity to Complain & 3.69 & 0.80 & .01 & $.1 I^{*}$ & $.10 *$ & .07 & .01 & -.06 & {$[.87]$} & & \\
\hline (7) Information Adequacy & 4.05 & 0.67 & $.12^{* *}$ & $.12^{* * *}$ & $.20 *$ & .03 & $-.12 * *$ & $-.10^{*}$ & $.36 * *$ & {$[.79]$} & \\
\hline (8) Consumer Frustration & 3.59 & 0.98 & .08 & .00 & .00 & -.08 & .00 & -.04 & $.32^{* *}$ & $.52 * *$ & {$[.76]$} \\
\hline
\end{tabular}

Note. Listwise $N=5 \mathrm{I}$; Cronbach's $\alpha$ is reported along the diagonal in brackets for the three scale variables.

${ }^{\dagger}$ Education, and Income were measured using an ordinal/categorical format where lower category numbers represent lower levels of the variable. Sex was measured categorically.

$* p<.05 . * * p<.01$

\section{Exhibit 5:}

Results from the One-way Analysis of Variance.

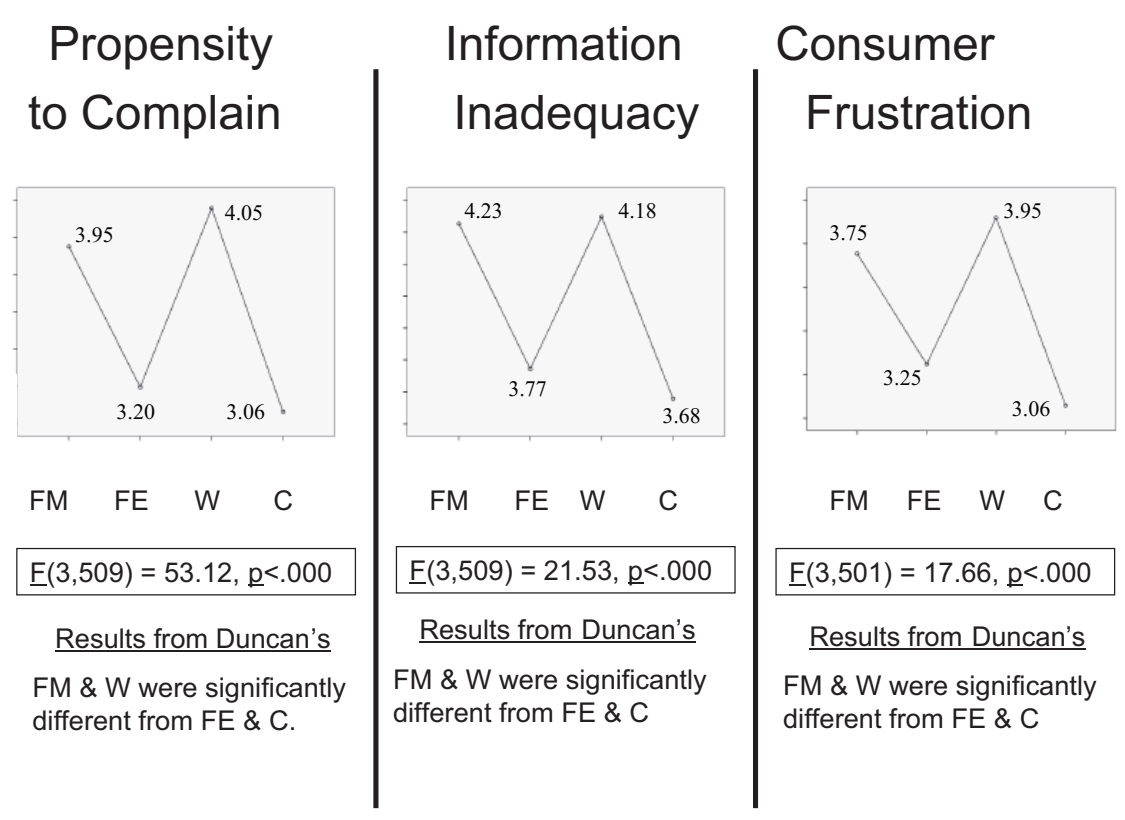

Note. Numbers on the charts are the mean responses for each dependent variable by communication mode. $F M=$ face-to-face with a manger; FE $=$ face-to-face with an employee; $\mathrm{W}=$ written letter, e-mail, or web; $\mathrm{C}=$ organizationally provided comment card.

with an employee and an organizationally provided comment card at the $p<.001$ level. This shows that guests who reported a lower level of information adequacy reported that organization-provided comment cards and face-to-face communication with employees were their preferred complaint channels. Likewise, guests who reported higher levels of information inadequacy preferred to complain to a manager or draft a written complaint.

Consumer frustration. The test of Research Question 3 produced a pattern of results similar to those of the previous two research questions. The one-way ANOVA results revealed significant differences among the means across the four communication modes, $F(3,509)=17.66, p<.001$. Results from Duncan's multiple range tests indicated that face-to-face communication with a manager and a written letter to management were statistically different from both face-to-face communication with an employee and an organizationally provided comment card at the $p<.001$ level. These results show that individuals reporting lower levels of guest frustration reported the use of organizationprovided comment cards, but contrary to the proposed 
media richness framework, guests who reported lower levels of frustration also indicated that they also prefer direct complaints to line-level employees. Respondents reporting higher levels of frustration regarding their service failure, however, preferred to make complaints to managers personally and complain in writing.

\section{Socio-Demographics}

Turning to Research Question 4, of the sociodemographic variables included in the model, only respondent sex and education level were significant in the multivariate model, while income level and dining frequency during the lunch meal period each showed significant correlations with some the dependent variables.

Education. Education level was significantly and positively correlated with propensity to complain $(r=.10, p=.02)$ and with perceptions of information inadequacy $(r=.20, p$ $<.001)$. Although significant, education level was negatively related to dining out for the lunchtime meal $(r=-.17$, $p<.001)$. This shows that generally more educated people were more likely to complain when dissatisfied and reported a higher need for information during service failures, but were less likely to eat lunch at a full-service restaurant. The one-way ANOVA analyses revealed a significant effect for both propensity to complain, $F(3,509)=9.28, p<.001$, and perceptions of information inadequacy, $F(3,509)=41.88, p$ $<.001$. Examining the degree levels, Duncan's multiple range tests indicated that those holding an associate's or technical degree reported a statistically lower propensity to complain along with lower information needs than those with high school diplomas, bachelor's degrees, or graduate degrees.

Education by communication channel. Because education was significant in the multivariate model, I conducted an additional $\chi^{2}$ test, which indicated that the respondents' education level was related to their preferred complaint channel. The $\chi^{2}$ test results, $\chi^{2}(9)=47.82, p<.001$, showed that those with graduate degrees preferred to complain via written communication, while no differences emerged for the other educational levels regarding this form of communication. Furthermore, there were no differences in the preference for face-to-face communication with line-level employees or the use of organizationally provided comment cards across all four educational levels measured. Last, regarding a preference for face-to-face communication with a manager, those holding associate's or technical degrees did not differ significantly from those with high school degrees or bachelor's and graduate degrees, but those holding bachelor's degrees and graduate degrees had a stronger, statistically significant preference for face-to-face communication with management compared with those holding only high school diplomas. One other difference by education level was that those holding associate's or technical degrees reported a lower propensity to complain and a lower need for information during service failures compared with the three other educational levels. This finding may have something to do with the work experiences associated with their educational background. Seventy percent of line-level food-service workers hold less than a high school diploma, while foodservice managers typically hold at a minimum a high school diploma, and some have attended college (Bureau of Labor Statistics, U.S. Department of Labor, 2014). ${ }^{3}$ Therefore, those with technical degrees are likely to have more direct experience with line-level employees and consumer complaints in their workplaces. I infer that this would make them less sensitive to the nuances of the complaint process as consumers.

I believe that the finding that respondents with graduate degrees were more inclined to write a letter to management (compared with the other three educational levels) reflects on their belief that they can communicate more effectively through this channel (based on efficacy and outcome expectations; Susskind 2000). While there were no differences across the four educational levels for the use of face-to-face communication with line-level employees and comment cards, those with bachelor's and graduate degrees showed a stronger preference for faceto-face communication with a manager, as compared with those with high school diplomas. As with the finding for written communication above, it appears that those holding college degrees prefer to by-pass interaction with line-level staff when complaining and deal directly with management.

Sex. The analysis indicated that women desired more information in the midst of a service failure, as indicated by the finding that only information inadequacy was significant, with females reporting a higher need than males, $M=4.11$ for women and $M=3.95$ for men; $t(509)=-2.03, p=.04$. This finding is consistent with research that shows men place more importance on instrumental facets of a service experience, while women focus more on the relational facets, which involve information exchange (Sanchez-Hernandez et al. 2010; Susskind 2004) and use both verbal and nonverbal cues in their communication. $T$ tests revealed that the women in this survey were 2.5 years older on average, $t(509)=-2.03, p=.04$, and dined out for dinner less frequently, $t(509)=3.64, p<.001$, than their male counterparts.

Sex by communication channel. Because sex was significant in the multivariate model (as was education), I conducted an additional $\chi^{2}$ test, which found that the respondents' sex was not associated with a single preferred communication channel to complain, $\chi^{2}(3)=2.07, p=.56$. 
Income. While income was not significantly related to the dependent variables, those earning higher salaries were older and more educated but ate their lunchtime meal out less frequently than others, as indicated by significant correlations with increased age $(r=.11, p=.01)$, reduced frequency of dining out for lunch $(r=-.12, p=.006)$, and greater education $(r=.28, p<.001)$. This also shows that those making less money ate lunch out more often. Despite the lack of significance for income in the multivariate model, I ran an additional $\chi^{2}$ test on communication channels, which found that income level was not associated with a preferred communication channel to complain, $\chi^{2}(9)=$ $13.57, p=.14$.

Age. Older respondents reported a significantly lower level of frequency for dining out for both the lunchtime meal $(r=$ $-.39, p<.001)$ and dinnertime meal $(r=-.38, p<.001)$, had higher incomes $(r=.11, p=.01)$, and reported a higher level of information inadequacy during service failures $(r=.12$, $p<.001)$.

\section{Discussion}

I mentioned above that a pure media richness approach did not completely apply in this case. I say this because face-toface communication - the richest form of communication-was not uniformly preferred by guests to address complaints, as the theory proposes. The results do show that guests prefer to use different communication channels to lodge complaints depending upon their perception of service experiences and their specific perceptions of complaints and the complaint process.

While those who favored richer communication channels reported higher levels of frustration, a propensity to complain, and information inadequacy (which the theory suggests means richer communication channels), these respondents viewed complaining directly to a manager as being essentially similar to writing a letter to someone high in the organization. Conversely, complaining to a line-level employee (which the theory views as a rich channel) was viewed similarly to using a comment card, which is the least rich channel of the four I measured here. These findings suggest that guests view complaints delivered at the line level differently than complaints delivered directly to management.

\section{Managerial Implications}

As a starting point, guests who are not satisfied with a service experience may not complain, depending upon the circumstances of the service failure and their own evaluation and processing of the service failure (Singh 1988; Sparks and Fredline 2007; Susskind 2000). This is a dynamic of the customer-server exchange that remains a challenge for operators to manage effectively. Managers generally want guests to complain when they are not fully satisfied with the service they receive, but encouraging complaints involves considerable uncertainty. When guests do decide that they are going to complain, this study shows that they take different approaches regarding to whom and how they complain based in part on their personal characteristics.

Complaints, just like compliments, are direct feedback from guests. Complaint management is an unavoidable part of the customer-server exchange and is a key to building long-term relationships between guests and operators. When a complaint is lodged, the service provider has a limited window of time to effectively address the complaint. As managers and employees gain a better understanding of how to react and respond to guest complaints, it (theoretically) becomes easier to remedy existing complaints and prevent similar problems that led to the complaint in the first place. The question is whether theory can become reality.

This study revealed that guests who were more likely complain, who have a higher need for information about a service failure, and who report a higher level of frustration prefer to complain directly to managers face-to-face or via written communication. These guests are not interested in generic comment cards nor are they likely to complain directly to employees. This shows in this case that restaurant guests - based on their perceptions of the complaint process - categorized complaints in two main ways: those directed toward management and those directed to the linelevel employees.

As I said, this finding differs from a strict media richness framework, but media richness theory does shed some new light on how restaurant consumers view and process complaints. A main tenet of this theory is that the person initiating the communication needs sufficient motivation to complain and needs to engage in such a way to attract the attention of the receiver (Robert and Dennis 2005). This aspect of media richness theory does help explain the findings. As a complaint involves a social confrontation (Susskind 2000, 2004), dealing directly with management requires more effort and, by implication, more motivation on the part of the guest. In addition, a complaint lodged directly to management reflects the premise that the guest is frustrated by a lack of control of the circumstances or a lack of adequate information (Guchait and Namasivayam 2012; Mittal, Huppertz, and Khare 2008; Susskind 2004). The logical conclusion here is that a sense of control emerges from interaction with management (Mittal, Huppertz, and Khare 2008), regardless of the richness of the communication channel used. In sum, I conclude that the distinctive nature of service experiences in a restaurant means that this deviation from a strict media richness theory framework makes sense for restaurants, particularly since restaurant service is notably different from the context of other media richness studies. 
Managers should realize that the guests who have chosen to complain to management, either face-to-face or via written communication, require some kind of response that is greater than what they perceive is available from their server or through a comment card. The roots of such complaints to management begin with the guests' belief that they should make such a complaint, in particular due to their frustration, and they likely require a substantial response that includes information about what went wrong and why. In addition to expressing appreciation for the feedback, managers should provide these complaining guests with a swift, factual accounting of the problem, proposed remedy, and how that would solve the problem now and prevent it from repeating in the future. This type of response acknowledges these guests' higher need for information regarding service failures and mitigates any looming frustration by ensuring that the problem is resolved to their satisfaction.

All of the above is (or should be) a fairly standard procedure for responding to complaints, but the point here is that these steps are supported by the theory and the findings of this study. Managers should, of course, also follow up with the guest after the service failure is corrected or send written correspondence to show the guest that you (as the manager) took ownership of the failure, truly valued their feedback, and sincerely wanted to correct the problem for them. As a reminder, this study indicates that it is important to ensure that you offer enough information about the failure and recovery to satisfy this subgroup's need for information.

None of the above is to say that complaints lodged via comment cards or directly to service staff members are not important or do not merit a response. All complaints and comments should be taken seriously and resolved as quickly and completely as possible. For direct complaints to linelevel service staff, the problem often can be resolved while the service experience is still in process. In such a situation, if the service failure is not complex and can easily be identified and addressed, it should be handled quickly at the line level, and a system should be in place to do so. This speaks to the issue of complaint severity, which was not addressed in this study but which may be connected to a guest's choice of a particular complaint channel.

\section{Study Limitations}

A chief limitation of this research is that it was a field-based survey project that did not take place in a restaurant. We collected our data at shopping malls to gain a large, diverse group of consumers who had been recent guests of fullservice restaurants. While this was a convenience sample, the sample accurately captured participants from the desired population. In addition, because data were collected from three disparate locations and at various times, the participants represented a decent cross-section of age, sex, and education. The screening process meant that sampling was not truly random, but it was essential that the participants meet the three qualifications for inclusion in the study. In addition, it should be noted that all three malls where the data were collected were located in communities supported by large research-based universities; therefore, the sample included a higher proportion of those holding (or working toward) bachelor's degrees and graduate degrees.

This study did not explore the use of social media to complain about service issues. Given the prevalence of social media in today's marketplace, future studies of complaint management and media richness should include measures of social media to complement existing research and examine the influences from this relatively new communication channel. Including social media as a communication channel may provide additional insight into complaint management.

Finally, I want to point out three pieces of data that were not collected in this investigation that would have added depth to the analysis and interpretation. These are the nature of the service failure the guest reported, the severity of the service failure, and whether their complaint was fully redressed to their satisfaction. I have included these variables in past studies (see, for example, Susskind 2005; Susskind and Viccari 2011), and they may very well have an effect on the guests' choices of the richness of a complaint channel.

The perishable nature of food service, the hospitality business, at large has a substantial effect on complaint dimensions. While this study only focused on consumers' complaints relative to restaurant experiences, it is possible that this study can inform managers of other hospitality and service-related businesses too. Understanding why and how your guests or customers complain are the first steps to being able to offer consistent, timely, and appropriate service recovery.

\section{Declaration of Conflicting Interests}

The author(s) declared no potential conflicts of interest with respect to the research, authorship, or publication of this article.

\section{Funding}

The author(s) received no financial support for the research, authorship, or publication of this article.

\section{Notes}

1. Third-party complaints - complaints addressed to a third party, not the seller-through social media sites have grown exponentially over the past several years. It is also important to note that when posting a third-party complaint through social media, there is no guarantee or expectation that redress will occur, as the service provider may never get wind of the complaint. Singh (1988) also notes that customers can also address 
third-party complaints to agencies or organizations designed to manage consumer complaint to get redress, such as the Better Business Bureau and other consumer advocacy groups. In these cases, consumers have a heightened expectation of some sort of resolution through these third parties. Therefore, guests who want a complaint resolved (opposed to just venting) would most likely complain directly to the seller.

2. It is important to note that frustration and aggression are two related, but separate, constructs (Neuman and Baron 1998). Psychologically speaking, aggression is a consequent of frustration, meaning that not all frustration leads to aggression.

3. Bureau of Labor Statistics Handbook (Bureau of Labor Statistics, U.S. Department of Labor, 2014) reported that 30 percent of restaurant managers did not hold a high school diploma.

\section{References}

Bagozzi, R. P. 1992. The self-regulation of attitudes, intentions, and behavior. Social Psychology Quarterly 55:178-204.

Berkowitz, L. 1989. Frustration-aggression hypothesis: Examination and reformulation. Psychological Bulletin 106 (1): 59-73.

Bureau of Labor Statistics, U.S. Department of Labor. 2014. Occupational outlook handbook, 2014-15 edition, food and beverage serving and related workers. http://www.bls.gov/ ooh/food-preparation-and-serving/food-and-beverage-serving-and-related-workers.htm (accessed February 11, 2014).

Daft, R. L., and R. H. Lengel. 1984. Information richness: A new approach to managerial information processing and organizational design. Research in Organizational Behavior 6:191233.

Daft, R. L., and R. H. Lengel. 1986. Organizational information requirements, richness, and structural design. Management Science 32:554-71.

Daft, R. L., R. H. Lengel, and L. K. Trevino. 1987. Message equivocality, media selection, and manager performance: Implications for information systems. MIS Quarterly 11: 355-66.

Day, R. L. 1984. Modeling choices among alternative responses to dissatisfaction. Advances in Consumer Research 11:496-99.

Dennis, A. R., and S. T. Kinney. 1998. Testing media richness theory in the new media: The effects of cues, feedback, and task equivocality. Information Systems Research 9 (3): 256-74.

Dennis, A. R., S. T. Kinney, and Y. C. Hung. 1999. Gender differences in the effects of media richness. Small Group Research 30 (4): 405-37.

Dollard, J., L. Doob, N. Miller, O. Mowrer, and R. Sears. 1939. Frustration and aggression. New Haven, CT: Yale University Press.

Fornell, C., and R. A. Westbrook. 1979. An exploratory study of assertiveness, aggressiveness, and consumer complaining behavior. Advances in Consumer Research 6: 105-10.

Guchait, P., and K. Namasivayam. 2012. Customer creation of products: Role of frustration in customer evaluations. Journal of Services Marketing 26: 216-24.

Harris, M. B. (1974). Mediators between frustration and aggression in a field experiment. Journal of Experimental Social Psychology10(5): 561-571.
Hinkin, T. R., and J. B. Tracey. 1999. An analysis of variance approach to content validation. Organizational Research Methods 2: 175-86.

Hui, M. K., and D. K. Tse. 1996. What to tell customers in waits of different lengths: An integrative model of service evaluation. Journal of Marketing 60 (2): 81-90.

Huppertz, J. W., E. Mower, and Associates. 2003. An effort model of first stage complaining behavior. Journal of Consumer Satisfaction, Dissatisfaction, and Complaining Behavior 16: 132-44.

Kahai, S. S., and R. B. Cooper. 1999. The effect of computermediated communication on agreement and acceptance. Journal of Management Information Systems 16 (Summer): 263-99.

Kahai, S. S., and R. B. Cooper. 2003. Exploring the core concepts of media richness theory: The impact of cue multiplicity and feedback immediacy on decision quality. Journal of Management Information Systems 19 (Summer): 165-88.

Kowalski, R. M. 1996. Complaints and complaining: Functions, antecedents, and consequences. Psychological Bulletin 119 (2): 179-96.

Maddux, J. E., L. W. Norton, and C. D. Stoltenberg. 1986. Selfefficacy expectancy, outcome expectancy, and outcome value: Relative effects on behavioral intentions. Journal of Personality and Social Psychology 51: 783-89.

Makoul, G., and M. E. Roloff. 1998. The role of efficacy and outcome expectations in the decision withhold relational complaints. Communication Research 25: 5-29.

Mattila, A. S., and H. Ro. 2008. Discrete negative emotions and customer dissatisfaction responses in a casual restaurant setting. Journal of Hospitality \& Tourism Research 32 (1): 89107.

Mittal, V., J. W. Huppertz, and A. Khare. 2008. Customer complaining: The role of tie strength and information control. Journal of Retailing 84 (2): 195-204.

Neuman, J. H., and R. A. Baron. 1998. Workplace violence and workplace aggression: Evidence concerning specific forms, potential causes, and preferred target. Journal of Management 24 (3): 391-419.

Park, S., and J. P. Allen. 2013. Responding to online reviews problem solving and engagement in hotels. Cornell Hospitality Quarterly 54 (1): 64-73.

Robert, L. P., and A. R. Dennis. 2005. Paradox of richness: A cognitive model of media choice. IEEE Transactions on Professional Communication 48 (1): 10-21.

Sanchez-Hernandez, R. M., V. Martinez-Tur, J. M. Peiro, and C. Moliner. 2010. Linking functional and relational service quality to consumer satisfaction and loyalty: Differences between men and women. Psychological Reports 106 (2): 598-610.

Schmitz, J., and J. Fulk. 1991. Organizational colleagues, media richness, and electronic mail. Communication Research 18 (4): 487-523.

Singh, J. 1988. Consumer complaint intentions and behavior: Definitional and taxonomical issues. Journal of Marketing 52 (1): 93-107.

Singh, J., and R. E. Wilkes. 1996. When consumers complain: A path analysis of the key antecedents of consumer complaint response estimates. Journal of the Academy of Marketing Science 24 (4): 350-65. 
Sparks, B., and L. Fredline. 2007. Providing and explanation for service failure: Context, content, and customer responses. Journal of Hospitality \& Tourism Research 31 (2): 241-60.

Stephens, N., and K. P. Gwinner. 1998. Why some people complain? A cognitive-emotive process model of consumer complaint behavior. Journal of the Academy of Marketing Science 26: $172-89$.

Susskind, A. M. 2000. Efficacy and outcome expectations related to guest complaints about service experiences. Communication Research 27 (3): 353-78.

Susskind, A. M. 2002. I told you so! Restaurant consumers' wordof-mouth communication. Cornell Hotel and Restaurant Administration Quarterly 43 (2): 75-85.

Susskind, A. M. 2004. Consumer frustration in the guest-server exchange: The role of attitudes toward complaining and information inadequacy related to service failures. Journal of Hospitality \& Tourism Research 28 (1): 200-23.

Susskind, A. M. 2005. A content analysis of consumer complaints, remedies, and repatronage intentions regarding dissatisfying service experiences. Journal of Hospitality \& Tourism Research 29 (2): 150-69.

Susskind, A. M., and A. E. Viccari. 2011. A look at the relationship between service failures, guest satisfaction, and repeat-patronage intentions of casual dining guests. Cornell Hospitality Quarterly 52 (4): 360-67.

Trevino, L. K., R. H. Lengel, and R. L. Daft. 1987. Media symbolism, media richness, and media choice in organizations. Communication Research 14: 553-74.

\section{Author Biography}

Alex M. Susskind is an associate professor at the School of Hotel Administration and a member of the Graduate Field of Communication at Cornell University, where he teaches courses in restaurant management. He earned his $\mathrm{PhD}$ in communication from Michigan State University with State University with cognates in organizational communication and organizational behavior where he also earned his MBA with a concentration in personnel and human relations. Susskind's research is based primarily in organizational communication and organizational behavior. He is currently researching: (a) the influence of customer-service provider interaction as it relates to organizational effectiveness and efficiency from the perspective of guests, employees and managers; (b) the influence of communication relationships upon individuals' work-related attitudes and perceptions surrounding organizational events and processes such as teamwork and downsizing; and (c) the influence of the BP Oil Spill on tourism in the Gulf Region. 